\title{
Case Report \\ Primary Hydatid Cyst of the Axillary Region: A Case Report
}

\author{
Mehrangiz Zangeneh, ${ }^{1}$ Mahmood Amerion, ${ }^{2}$ S. Davar Siadat, ${ }^{3}$ and Mohsen Alijani ${ }^{1}$ \\ ${ }^{1}$ Department of Infectious Diseases, Islamic Azad University, Tehran Medical Branch, Tehran, Iran \\ ${ }^{2}$ Department of General Surgery, Islamic Azad University, Tehran Medical Branch, Tehran, Iran \\ ${ }^{3}$ Department of Microbiology, Pasteur Institute, Tehran, Iran
}

Correspondence should be addressed to Mehrangiz Zangeneh, zangeneh4@yahoo.com

Received 8 July 2012; Revised 30 September 2012; Accepted 30 September 2012

Academic Editor: Nima Rezaei

Copyright (๑) 2012 Mehrangiz Zangeneh et al. This is an open access article distributed under the Creative Commons Attribution License, which permits unrestricted use, distribution, and reproduction in any medium, provided the original work is properly cited.

\begin{abstract}
Introduction. Hydatid disease is a disease caused by the cestode Echinococcus. Echinococcus granulosus is the most common Echinococcus species affecting human. It may affect any organ and tissue in the body, most in the liver and lung. Disease is endemic in some regions of the world, and is common in Iran. Primary hydatid cyst of the axillary region is an unusual and rare localization of hydatid disease. So far, only sixteen cases have been published in the all medical literature. Case Report. Herein, we present a 33 -year-old woman because of a mass in the axillary region of four months duration. Axillary ultrasonography showed a thick wall cystic lesion. No abnormality was found in mammographic examination of either breast, or in abdominal ultrasonography and chest X-ray. The mass was excised for pathological examination that showed a typical laminated membrane of hydatid cyst. Postoperative IgG- ELISA serology in this case was negative. Based on pathology an axillary hydatid cyst was diagnosed. Conclusion. Hydatid cyst should be considered in endemic areas in patients presenting with a soft tissue mass in the axillary region.
\end{abstract}

\section{Introduction}

In human, three forms of echinococcosis are known to occur: cystic echinococcosis, caused by Echinococcus granulosus, alveolar echinococcosis, caused by Echinococcus multilocularis, and polycystic Echinococcosis due to Echinococcus vogeli or Echinococcus oligarthrus. Hydatid disease is a parasitic disease usually caused by the larval stage of a small zoonotic tapeworm primarily found in dogs Echinococcus granulosus [1]. Echinococcus granulosus (cystic echinococcosis) is the most common species, E. granulosus has worldwide distribution and is endemic in many countries, especially the Mediterranean region, Australia, South America, the Middle East, South Africa, and Eastern Europe [1-3]. Iran is also an endemic area for hydatid diseases, the prevalence of cystic echinococcosis in humans detected by ultrasound ranges from less than $0.5 \%$ to $1.5 \%$. Human seropositivity was greater than $5 \%$ in the west and southwest of the Islamic Republic of Iran, with $2-18 \%$ seroprevalence in nomadic groups $[4,5]$. The hydatid cysts of E. granulosus tend to form in the liver (50\% to $70 \%$ of patients) or lung $(20 \%$ to $30 \%)$ but may through the capillary systems reaches the general circulation and passes to all viscera and soft tissues. For this reason, hydatid cysts may arise in atypical sites such as the brain, heart, orbit, urinary bladder, chest wall, subcutaneous tissue, tibia, parotid gland, breast, cervicofacial region, thyroid, and in any organ of the body $(10 \%)[1,3,6,7]$. The diagnostic methods include imaging techniques, mainly X-ray for lung echinococcosis, ultrasound and computed tomography examination for abdominal echinococcosis and other affected organs, and immunodiagnostic tests (enzyme-linked immunosorbent assay (ELISA), IFAT, and immunoblot) for confirmation. IgG-ELISA is about $90 \%$ sensitive for liver cyst infection but less sensitive for lung $(80 \%)$ or other organ involvementand (90\%), and its specificity is $90 \%$ [1].

Symptoms are often absent, and in many cases infection is detected only incidentally by imaging studies. Its symptoms depending on the host organ, location, its effect on adjacent structures, complications due to rupture, secondary infections, and immunological reactions caused by the cyst $[1,5]$. Primary axillary hydatid disease is rare even in the endemic regions, we could find only sixteen case reports in the literature $[3,6,8-21]$. In this paper, we report a 


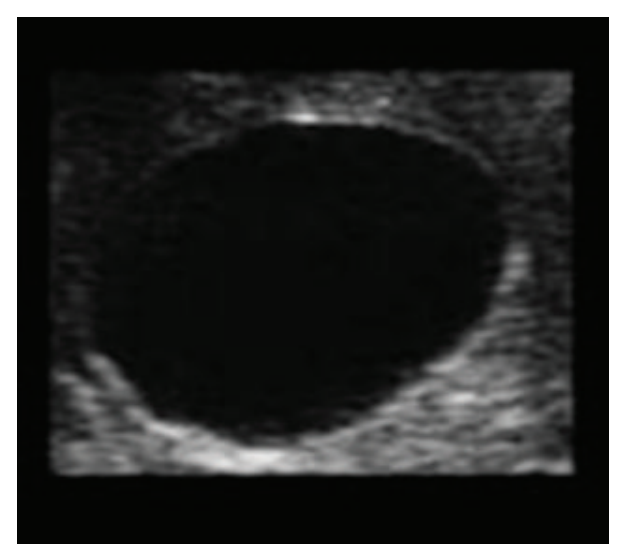

FIGURE 1: Ultrasound image of axillary cyst.

case of a primary hydatid disease which originated in the subcutaneous tissue in the right axillary region in a 36-yearold woman.

\section{Case Report}

A 33-year-old woman in 2010 was presented to our hospital with painless right axillar swelling of four-month duration. She had no history of breast mass, fever, other symptoms, or other mass, and also had no history of hydatid cyst. On physical examination, a firm to hard $5 \times 5 \mathrm{~cm}$ mobile mass was noted in the right axilla. Laboratory investigations were done which revealed normal blood counts and biochemical result. Ultrasound showed a $5 \times 5 \mathrm{~cm}$ thick wall cystic lesion comparable with type CE1 of WHO classification (Figure 1). No abnormality was found in mammographic examination of either breast. In this case it was difficult to differentiate a cyst with uncharacteristic imaging findings (type CE1 of WHO Classification based on ultrasound) from simple subcutaneous cyst, haematoma, necrotic tumor, or lymph node based on ultrasound. Under general anesthesia, the entire cyst was excised without rupture and sent for histopathological examination. On macroscopic examination, a unilocular cyst with a hard fibrotic wall was seen. Microscopic examination revealed the presence of a typical laminated membrane of hydatid cyst (Figure 2). The hydatid IgG-ELISA test in our case was negative. Radiographs of chest, spine, and long bones were done for evaluation of hydatid in organs and all were normal. Abdominal ultrasound examination was normal. The patient was discharged from the hospital with albendazole $400 \mathrm{mg}$ twice a day for four weeks. During one-year followup, examinations since her surgery have shown no relapse of hydatidosis.

\section{Discussion}

Hydatid disease is a common clinical pathology in many parts of the world. The main species pathogenic for humans in Mediterranean and Southern European countries is Echinococcus granulosus $[1,2]$. Hydatid cysts most often develop in the liver and lung. primary axillary hydatid disease is rare, as shown in Table 1 , we could find only sixteen previous case reports in the medical literature $[3,6,8-21]$ (Table 1).

Hydatid cysts grow 5 to $10 \mathrm{~cm}$ in size within the first year and can survive for years or even decades. The cyst may be present for many years in the organ in which it is located with no clinical symptoms or signs, and sometimes it may exhibit clinical symptoms depending on the size and location of the cyst and the pressure of the growing cyst $[1,6]$. The sonographic and tomographic appearances of subcutaneous hydatid disease such as axillary hydatid cyst are similar to those in other organs. Hydatid cyst may be unilocular at earlier stages, whereas older cysts are usually multilocular. They may either be made up of daughter cysts or have a solid appearance made up of multiple septated cysts. However, hyperintense hydatid cysts in the axillary region can be misdiagnosed as a soft tissue tumor or lymphadenopathy. As Iran is an endemic area for hydatid disease, this should be in the differential diagnosis for patients presenting with tissue masses including haematoma, abscess, sarcoma, lymphadenopathy, breast cancer, or metastatic lesions [1, $3,18]$. Infection is suspected based on imaging studies (ultrasonography, CT, and MRI), and it may be confirmed by a specific enzyme-linked immunosorbent assay (ELISA) and Western blot serology. Ultrasonography is an easy available, and affordable with high diagnostic sensitivity imaging test for screening of hydatid cyst in endemic areas and in family members based on WHO classification. The sonographic imaging in our case showed a simple cystic lesion comparable with type CE1 of WHO Classification and did not confirm a diagnosis of hydatid cyst; it is difficult to differentiate a cyst with uncharacteristic imaging findings from simple subcutaneous cyst, haematoma, necrotic tumor, or lymph node based on ultrasound. Immunodiagnostic tests (enzyme-linked immunosorbent assay (ELISA), IFAT, and immunoblot) are used for confirmation. IgG-ELISA is about 90\% sensitive for liver cyst infection but less sensitive for lung (80\%) and other organ involvement (90\%), and its specificity is $90 \%$ [1]. Postoperative IgG-ELISA test in this case was negative. Abdominal ultrasonography and a plain chest radiography are mandatory to detect liver and lung involvement. Chest X-rays and imaging studies showed no other involvement in our patient. In routine practice, the accurate diagnosis in patient with soft tissue hydatidosis is frequently delayed until histopathologic examination after surgery. In this case, for accurate diagnosis, the entire cyst was excised.

Today, treatment options for CE (cystic echinococcosis) include surgery, PAIR (puncture, aspiration, injection, and reaspiration), and chemotherapy. Optimal treatment of hydatid cysts is surgical resection to remove the cyst. The main purpose of the surgery is to prevent the patient from complications such as compression of surrounding structures, infection or rupture of the cyst [1, 7]. Total cystectomy with fibrous adventitia which allows removal of all parasitic elements without spillage of the contents of the cyst, is curative treatment for soft tissue hydatidosis. We performed total cystectomy without rupture in spite of the anatomical distortion of the axillary region. Antiparasitic 

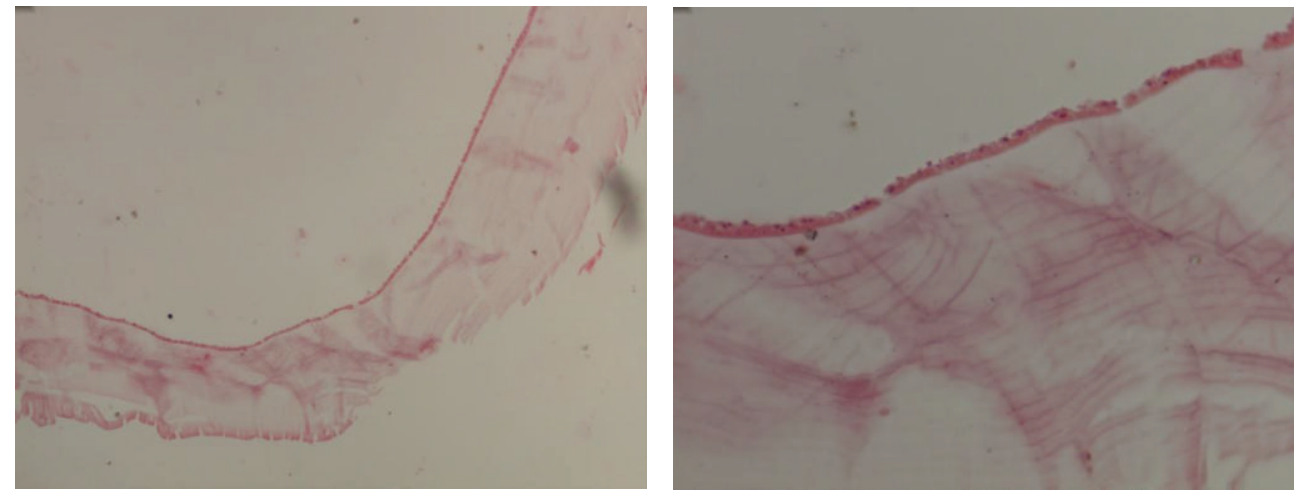

FIGURE 2: Section of cyst wall showing germinal epithelium and underlying laminated membrane (haematoxylin-eosin stain, magnification $\times 10)$.

TABLE 1: Reported cases of hydatid cysts of the axilla.

\begin{tabular}{|c|c|c|c|c|c|c|c|}
\hline Author & Year & Age/gender & Origin of cysts & Daughter cysts & Organ involvement & Screening & Follow \\
\hline Thomson [8] & 1899 & NA & Axillary & NA & NA & NA & NA \\
\hline Lamotte et al. [9] & 1967 & $32 / \mathrm{M}$ & Right axillary vein & Multiple & None & CXR & NA \\
\hline Zamfir et al. [10] & 1997 & $11 / \mathrm{F}$ & Left neurovascular & None & pulmonary & CXR, US & NA \\
\hline Navarro Martín et al. [11] & 1998 & $84 / \mathrm{M}$ & Subcutaneous & Multiple & None & CXR, US & NA \\
\hline Mayol Martínez et al. [12] & 1994 & $67 / \mathrm{F}$ & Muscle & Multiple & None & CXR,US & NA \\
\hline Ekrem Unal et al. [13] & 2001 & $53 / \mathrm{F}$ & Right pectoral M & None & None & MRI, CT & 9 months \\
\hline Dilege et al. [14] & 2003 & $15 / \mathrm{F}$ & Right axillary region & NA & Pulmonary & CXR, CT & NA \\
\hline Losanoff et al. [15] & 2004 & $38 / \mathrm{M}$ & Subcutaneous tissue & NA & None & NA & NA \\
\hline Sain Guven et al. [16] & 2004 & & & & & & \\
\hline Borovik et al. [17] & 2006 & $31 / \mathrm{F}$ & Left axillary & Multiple & None & CXR, CT & 6 months \\
\hline Singh et al. [18] & 2009 & $28 / \mathrm{M}$ & Left lateral chest wall & NA & None & CXR, CT & 8 years \\
\hline Ünalp et al. [3] & 2011 & $48 / \mathrm{F}$ & Left axillary fossa & Multiple & None & CXR, US, CT & 6 months \\
\hline Ozsoy et al. [6] & 2011 & $45 / \mathrm{F}$ & The axillary region & None & None & CXR, US, CT & 1 year \\
\hline Ruso et al. [19] & 2011 & $84 / \mathrm{F}$ & Cervicoaxillary region & Multiple & None & CXR, US, CT & 5 years \\
\hline Arsalane et al. [20] & 2012 & $43 / \mathrm{M}$ & Left axilla & Multiple & None & CXR, US, CT & NA \\
\hline Saylam et al. [21] & 2012 & $36 / \mathrm{F}$ & Right axillar & None & None & CXR, US & 17 months \\
\hline
\end{tabular}

F: female, M: male, CT: computed tomography, CXR: chest X-ray, LP: laparoscopy, RS: radionuclide scintigraphy, US: ultrasonography, NA: data not available, MRI: magnetic resonance Imaging.

medication is widely used postoperatively and preoperatively for the purpose of cyst size reduction and to limit the risk of intraoperative dissemination of daughter cysts. All patients are treated with albendazole $10 \mathrm{mg} / \mathrm{kg} / \mathrm{day}$ for at least two weeks preoperatively, and this is continued postoperatively for four weeks [22]. However, the experience with scolicidal agents such as albendazole $(400 \mathrm{mg} / \mathrm{kg})$ and praziquantel $(50 \mathrm{mg} / \mathrm{kg})$ or a combination of these drugs in the treatment of soft tissue hydatid disease is very limited and results of the medical treatment in the hydatidosis are unclear $[23,24]$. We gave the patient albendazole $400 \mathrm{mg}$ twice a day for four weeks postoperatively.

In conclusion, hydatid disease is a widespread public health problem in developing countries especially in endemic regions; therefore, it should be considered in the differential diagnosis of a palpable mass in the axillary region.

\section{Conflict of Interests}

The authors declare that they have no conflict of interests.

\section{Consent}

Written informed consent was obtained from the patient for publication of this case report and accompanying images.

\section{References}

[1] WHO/OIE Manual on echinococcosis in human and animals: a Public Health Problem of Global Concern. Edited by J. Eckert, M. A. Gemmell, F.-X. Meslin and Z. S. Pawlowski, 2002, http://www.oie.int/. 
[2] P. S. Craig, D. P. McManus, M. W. Lightowlers et al., "Prevention and control of cystic echinococcosis," The Lancet Infectious Diseases, vol. 7, no. 6, pp. 385-394, 2007.

[3] H. R. Ünalp, E. Kamer, T. Rezanko, Ö. Kılıç, M. Tunakan, and M. A. Önal, "Primary hydatid cyst of the axillary region: a case report,” Balkan Medical Journal, vol. 28, no. 2, pp. 209-211, 2011.

[4] First WHO report on neglected tropical diseases 2010: working to overcome the global impact of neglected tropical diseases. WHO/HTM/NTD/2010. 1.

[5] A. Zamani and S. Kalikas, "Hydatid cyst of parotid gland: a case report," Iranian Journal of Pediatrics, vol. 16, no. 1, 2006.

[6] M. Ozsoy, C. Keles, M. Kahy, and G. Keles, "Primary echinococcal cyst in the axillary region," Journal of Infection in Developing Countries, vol. 5, no. 11, pp. 825-827, 2011.

[7] I. Iynen, O. Sogut, M. E. Guldur, R. Kose, H. Kaya, and F. Bozkus, "Primary hydatid cyst: an unusual cause of a mass in the supraclavicular region of the neck," Journal of Clinical Medicine Research, vol. 3, no. 1, pp. 52-54, 2011.

[8] P. J. Thomson, M. R. C. S. ENG., and L. R. C. P. Lond, "Hydatid cyst of the axilla in a child," The Lancet, vol. 153, no. 3932, pp. 25-26, 1899.

[9] M. Lamotte, J. Perrotin, A. Julliard, and G. Timsit, "Hydatid cysts of the soft tissues. Apropos of a case of hydatid cyst of the axilla," Annales de Chirurgie, vol. 21, no. 23, pp. 1463-1467, 1967 (French).

[10] T. Zamfir, R. Bălănescu, T. Pătrăcuş et al., “The diagnosis and surgical treatment in the case of 2 rare sites of hydatid cyst in children," Chirurgia, vol. 92, no. 6, pp. 413-415, 1997 (Romanian).

[11] L. M. Navarro Martín, J. Pardo Lledìas, I. Galindo Pérez, and R. Querol Prieto, "Medicine in images. Incidental diagnosis of a mass subcutaneously located in the axillary region," Revista Clínica Española, vol. 198, no. 10, pp. 703-704, 1998 (Spanish).

[12] J. Mayol Martínez, P. J. González Noguera, R. Peromingo Fresneda, and J. Alvarez Fernández-Represa, "Mass localized in the axilla," Revista Clínica Española, vol. 194, no. 3, pp. 199200, 1994 (Spanish).

[13] A. Ekrem Unal, S. Can Ulukent, S. Bayar, A. Demirkan, and H. Akgül, "Primary hydatid cyst of the axillary region: report of a case," Surgery Today, vol. 31, no. 9, pp. 803-805, 2001.

[14] S. Dilege, M. Aksoy, I. Okan, A. Toker, G. Kalayci, and M. Demiryont, "Hydatid cystic disease of the soft tissues with pulmonary and hepatic involvement: report of a case," Surgery Today, vol. 33, no. 1, pp. 69-71, 2003.

[15] J. E. Losanoff, B. W. Richman, and J. W. Jones, "Primary hydatid cyst of the axilla," ANZ Journal of Surgery, vol. 74, no. 5, pp. 393-394, 2004.

[16] G. Sain Guven, H. Simsek, B. Cakir, O. Akhan, and O. Abbasoglu, "A hydatid cyst presenting as an axillary mass," The American Journal of Medicine, vol. 117, no. 5, pp. 363-364, 2004.

[17] A. Borovik, D. Massasso, and K. Gibson, "Axillary hydatid disease," The Medical Journal of Australia, vol. 184, no. 11, p. $585,2006$.

[18] S. Singh, S. Khichy, M. Singh, and J. Singh Gill, "Recurrent solitary hydatid cyst of the subcutaneous tissue," Indian Journal of Surgery, vol. 71, no. 3, pp. 162-164, 2009.

[19] L. Ruso, G. Rodriguez, A. Gatti et al., "Primary cervicoaxillary hydatid disease," Cirugia y Cirujanos, vol. 79, pp. 306$312,2011$.

[20] A. Arsalane, M. El Hammoumi, F. El Oueriachi, A. Traibi, A. Darbi, and E. H. Kabiri, "Primary axillary hydatid cyst,"
General Thoracic and Cardiovascular Surgery, vol. 60, no. 6, pp. 359-362, 2012.

[21] B. Saylam, V. Vural, A. P. Duzgun, M. V. Ozer, and F. Coskun, "Primary hydatid cyst of the axilla: report of a case," Medical Principles and Practice, vol. 21, no. 1, pp. 79-81, 2012.

[22] O. Akhan, B. Gumus, D. Akinci, M. Karcaaltincaba, and M. Ozmen, "Diagnosis and percutaneous treatment of soft-tissue hydatid cysts," CardioVascular and Interventional Radiology, vol. 30, no. 3, pp. 419-425, 2007.

[23] A. E. Mohamed, M. I. Yasawy, and M. A. Al Karawi, "Combined albendazole and praziquantel versus albendazole alone in the treatment of hydatid disease," Hepato-Gastroenterology, vol. 45, no. 23, pp. 1690-1694, 1998.

[24] M. Jamshidi, M. Mohraz, M. Zangeneh, and A. Jamshidi, "The effect of combination therapy with albendazole and praziquantel on hydatid cyst treatment," Parasitology Research, vol. 103, no. 1, pp. 195-199, 2008. 


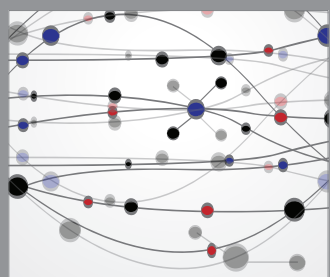

The Scientific World Journal
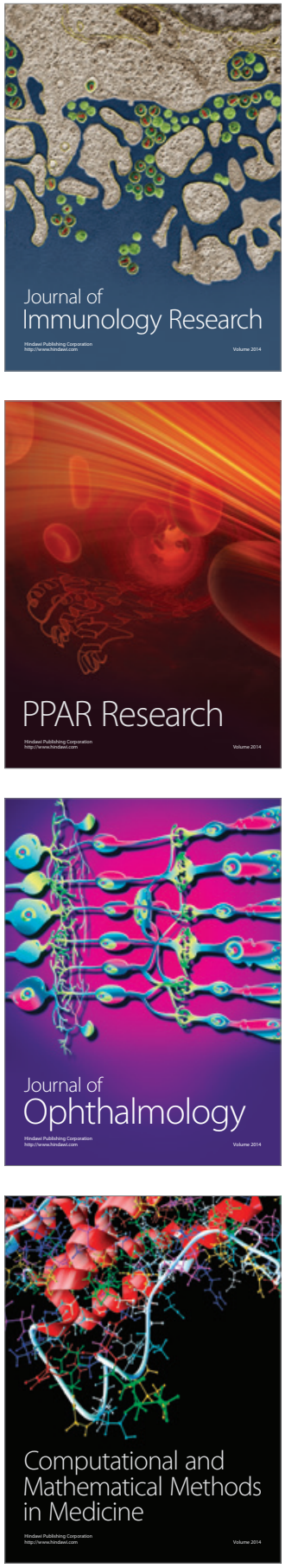

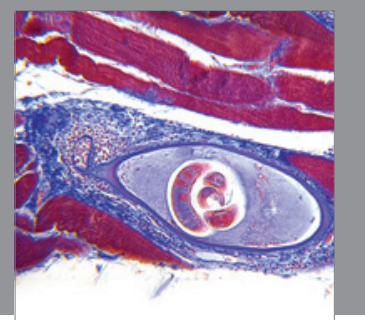

Gastroenterology

Research and Practice
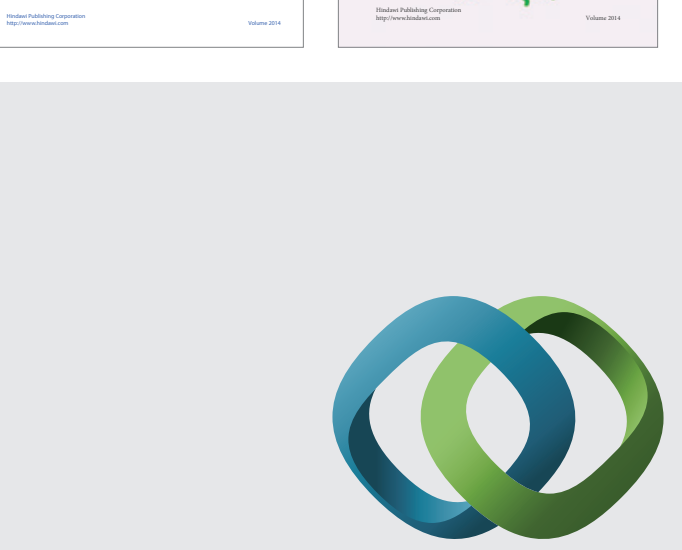

\section{Hindawi}

Submit your manuscripts at

http://www.hindawi.com
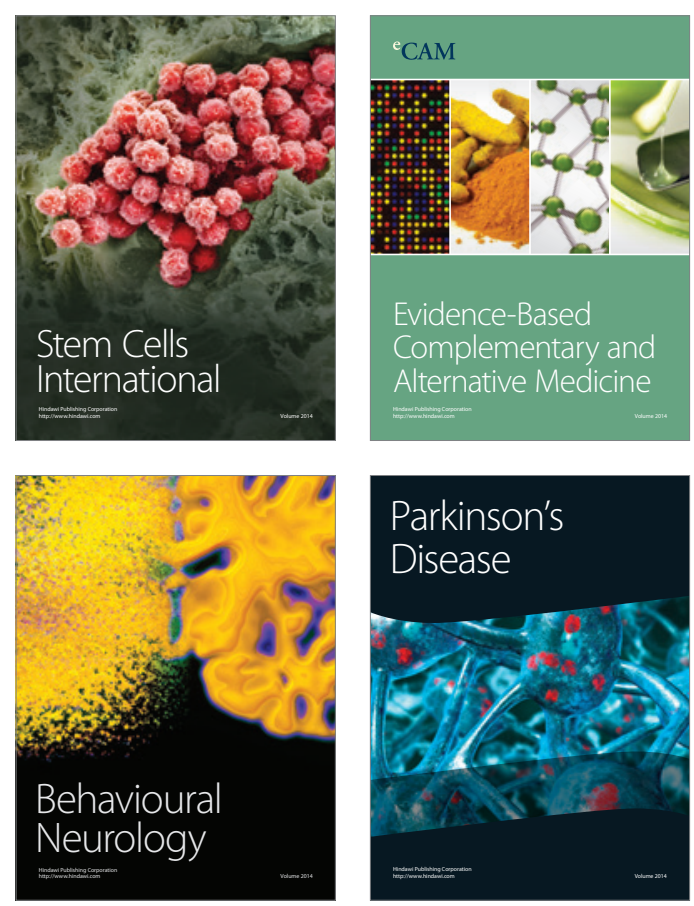

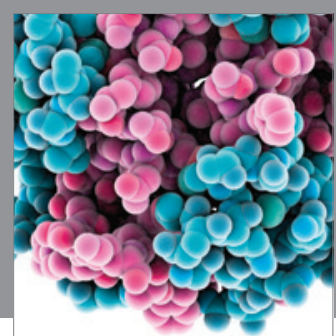

Journal of
Diabetes Research

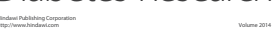

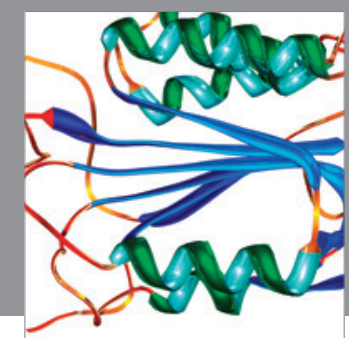

Disease Markers
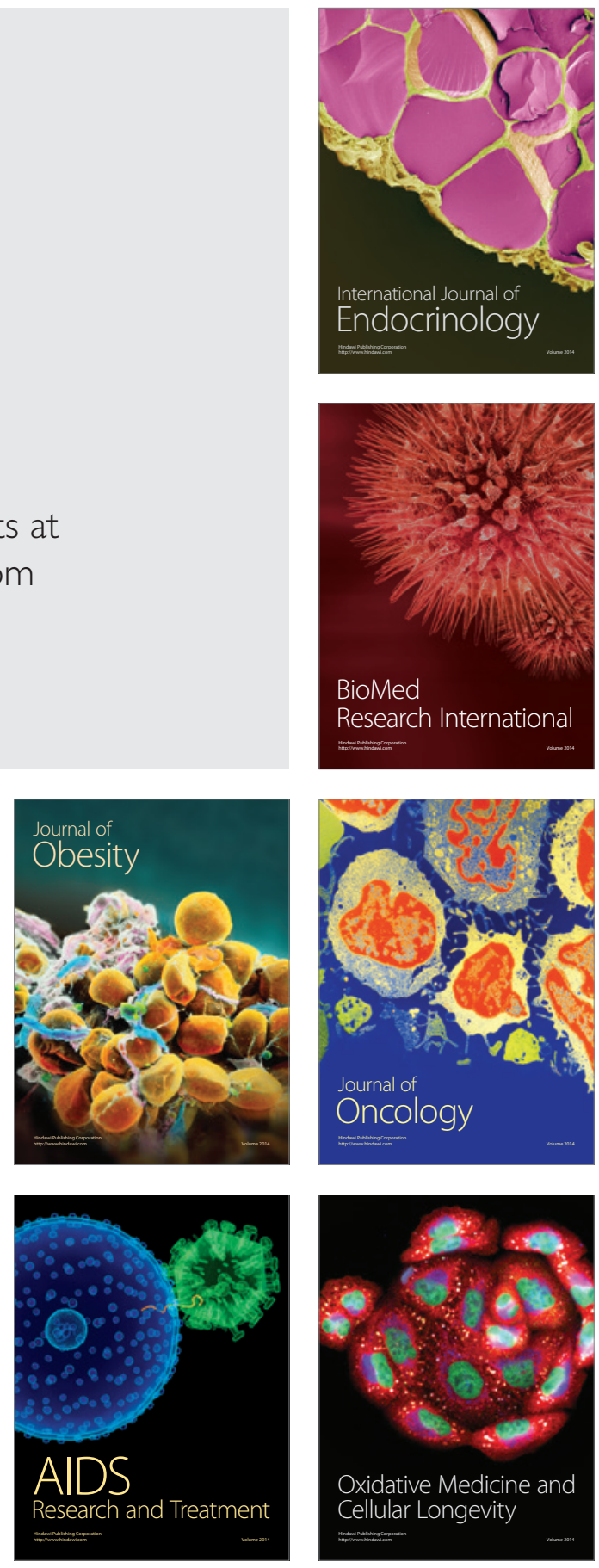